BNL 52054

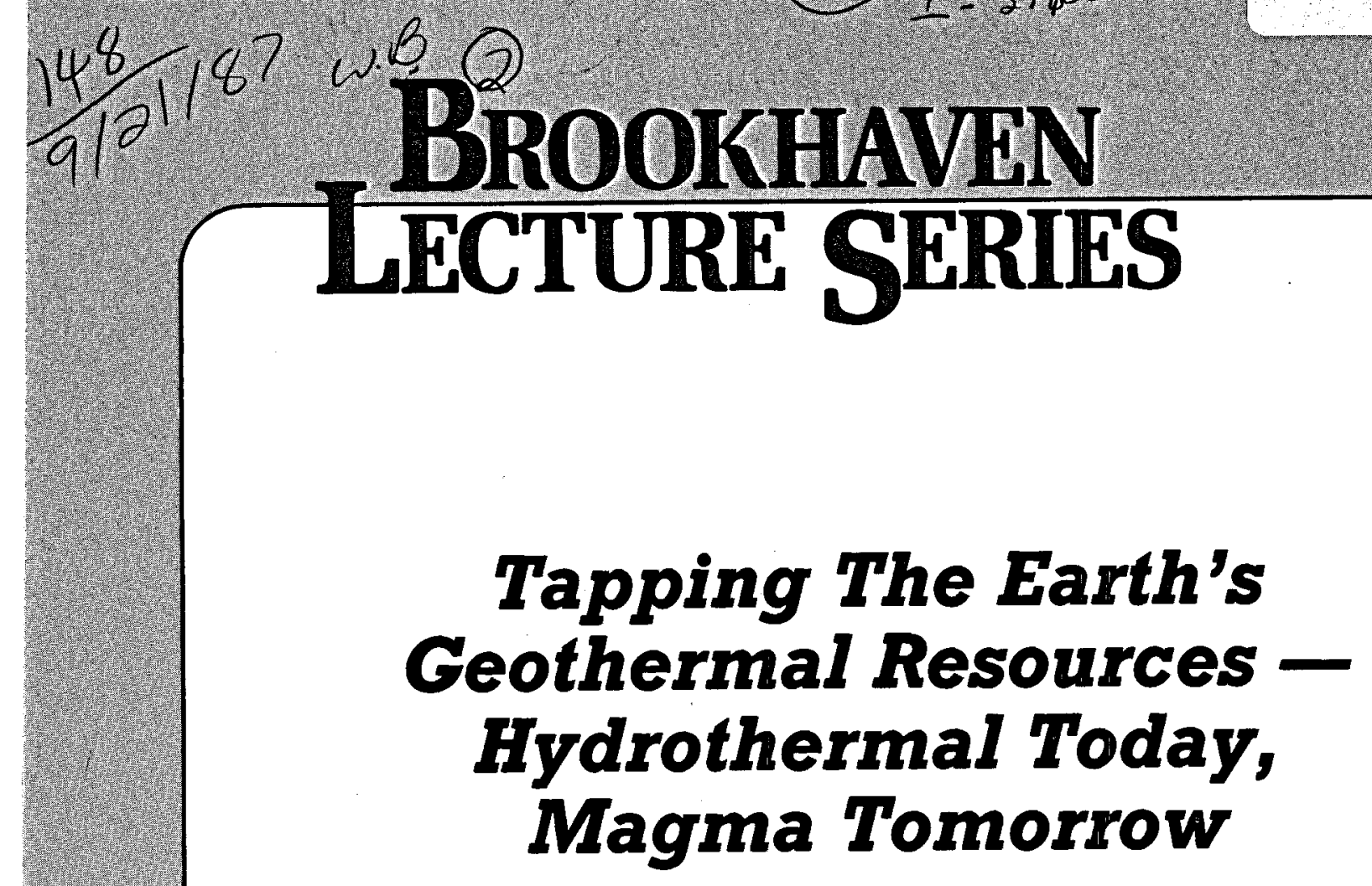




\section{DISCLAIMER}

This report was prepared as an account of work sponsored by an agency of the United States Government. Neither the United States Government nor any agency Thereof, nor any of their employees, makes any warranty, express or implied, or assumes any legal liability or responsibility for the accuracy, completeness, or usefulness of any information, apparatus, product, or process disclosed, or represents that its use would not infringe privately owned rights. Reference herein to any specific commercial product, process, or service by trade name, trademark, manufacturer, or otherwise does not necessarily constitute or imply its endorsement, recommendation, or favoring by the United States Government or any agency thereof. The views and opinions of authors expressed herein do not necessarily state or reflect those of the United States Government or any agency thereof. 


\section{DISCLAIMER}

Portions of this document may be illegible in electronic image products. Images are produced from the best available original document. 


\section{Tapping The Earth's Geothermal Resources Hydrothermal Today, Magma Tomorrow}

Lawrence E. Kukacka

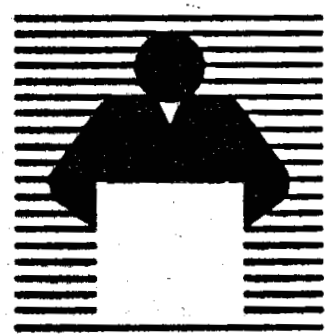

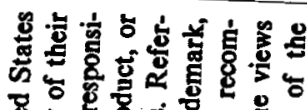

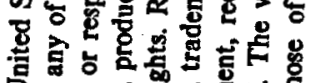

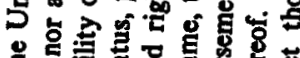

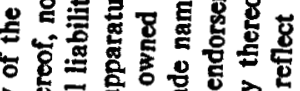
可要

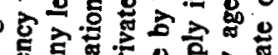

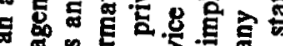

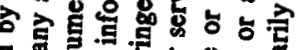

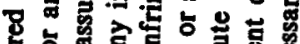

Number 230

December 17, 1986

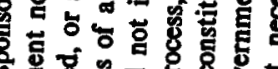

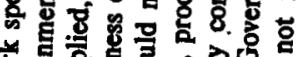

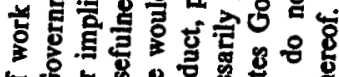
过安

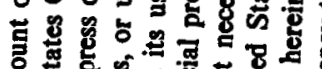

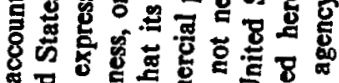

ร

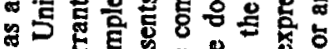

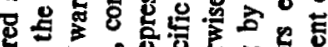

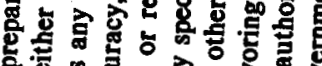

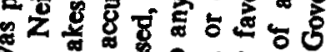

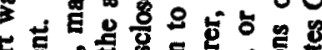

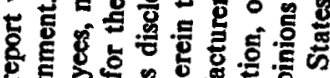

능

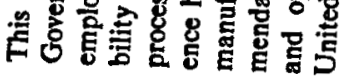

.

\section{BROOKHAVEN NATIONAL LABORATORY}

Associated Universities, Inc.

Under Contract No. DE-ACO2-76CHO0016 with the

United States Department of Energy

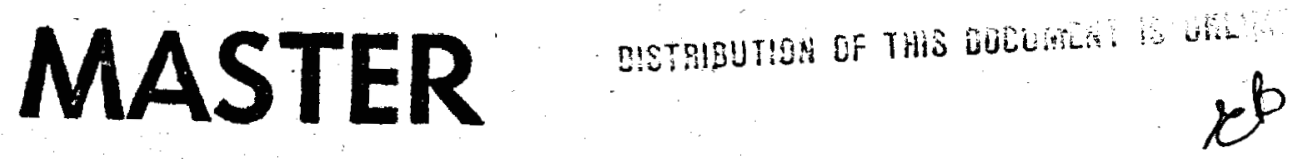




\section{DISCLAIMER}

This report was prepared as an account of work sponsored by an agency of the United States Government. Neither the United States Government nor any agency thereof, nor any of their employees, nor any of their contractors, subcontractors, or their employees, makes any warranty, express or implied, or assumes any legal liability or responsibility for the accuracy, completeness, or usefulness of any information, apparatus, product, or process disclosed, or represents that its use would not infringe privately owned rights. Reference herein to any specific commercial product, process, or service by trade name, trademark, manufacturer, or otherwise, does not necessarily constitute or imply its endorsement, recommendation, or favoring by the United States Government or any agency, contractor or subcontractor thereof. The views and opinions of authors expressed herein do not necessarily state or reflect those of the United States Government or any agency, contractor or subcontractor thereof.

Printed in the United States of America Available from

National Technical Information Service U.S. Department of Commerce 5285 Port Royal Road Springfield, VA 22161

NTIS price codes:

Printed Copy: A02; Microfiche Copy: A01

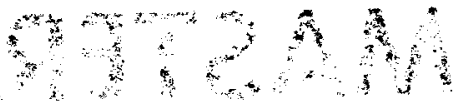




\title{
Tapping The Earth's Geothermal Resources - Hydrothermal Today, Magma Tomorrow
}

\author{
Lawrence E. Kukacka
}

In October of 1971, Meyer Steinberg presented lecture 105, "Concrete Polymer Materials, a Goal Oriented Program," which served as the basis for our Geothermal Program. One of our sponsors then was the Office of Saline Water (OSW) of the Department of Interior. The OSW had an interest in developing water desalination plants, and one of their requirements was a cementitious material that would impart corrosion resistance to flash distillation units.

A constructional material was needed, which could withstand distilled water and sea water at temperatures up to about $125^{\circ} \mathrm{C}$. To meet these characteristics, we developed a styrene trimethylolpropane trimethacrylate-based polymer concrete, and we used it to line several flash distillation units of a pilot plant in Freeport, Texas. Unfortunately, the durability of the OSW was poorer than the durability of our polymer concrete, and that organization was defunctionalized shortly thereafter, terminating our program. In 1976, at the height of the Department of Energy's (DOE) interest in alternate energy technologies, we submitted a proposal to the Division of Geothermal Energy to upgrade the capabilities of the material to withstand hypersaline brines.

Such hypersaline brines contain about 300,000 to 350,000 parts per million of total dissolved solids at temperatures up to about $300^{\circ} \mathrm{C}$ and $\mathrm{pH}$ as low as three to three and a half. People have characterized these fluids as the most chemically aggressive found in nature.

The 1976 proposal was accepted and a year later, we were asked by DOE to develop and implement a program on high temperature cements for geothermal well completions. The program was a success and in 1978, DOE asked us to assume overall responsibility for all of their geothermal materials efforts. At the present, we have programs on cements, lost-circulation control materials, high temperature elastomers, metal liners for well casing, and corrosion effects of the organic working fluids used in power plant cycles.
This paper will discuss several topics. I will describe the geothermal resource, its formation, its size, what it consists of and where it is. I will use terms like hydrothermal, geopressure, hot dry rock and magma resources.

Hydrothermal resources consist of hot water with temperatures varying between $50^{\circ}$ and $300^{\circ} \mathrm{C}$ and salinities up to $300,000 \mathrm{ppm}$. $\mathrm{A}$ geopressure resource is a form of hydrothermal; the main difference is that large quantities of methane are dissolved in hot water. Some of these concentrations are as high as $\mathbf{4 0}$ to $\mathbf{5 0}$ standard cubic feet per barrel of brine.

Next, I will discuss hot dry rock, which as the name implies, is hot, but has no fluid contained in it. Temperatures of interest are up to about $300^{\circ} \mathrm{C}$. The temperature obtained is determined by how deep in the earth we drill and where we drill. The fourth resource is magma; if we actually drill into it, the temperature may be $900^{\circ} \mathrm{C}$.

The paper will continue with details of energy extraction and conversion. I will explain how we get the heat out of the earth and how we convert that heat energy to electrical energy. Finally, I will discuss a little bit about Brookhaven materials activities, and I will conclude with the economics of geothermal power.

There is a tremendous amount of energy stored in the earth. At the center of the earth, which is at a depth of about 4,000 miles, the temperature is in excess of $4,000^{\circ} \mathrm{C}$, but most of the heat energy in the earth is either too deep or too diffusively spread to be felt on the surface of the earth.

There are, however, some places where it is apparent that geothermal resources exist. One is the volcano. Here, molten rock from the mantle of the earth spurts out onto the surface at temperatures in excess of $1100^{\circ} \mathrm{C}$. Less spectacular manifestations of geothermal energy are geysers and fumaroles.

The utilization of geothermal energy is not new. Prehistoric man cooked in hot springs; Romans heated their baths; France built heat- 
ing systems in the Middle Ages, and wars were fought among Italian city states over mineral rights from hot springs. The modern geothermal era began in 1812 in Larderello, Italy, where boric acid was made from the dried residues of hot springs. In 1913 a 250 kilowatt power plant was built at Larderello. Today, about $\mathbf{4 0 0}$ megawatts are produced at that site.

In the United States, at the turn of the century, district heating systems were built. For example, in Boise, Idaho, a district heating system was constructed in the mid 1890's. The first power plant of any consequence in the United States, a twelve and a half megawatt plant, was built about 1960 at the Geysers. Today, that site produces about 1200 megawatts.

Since then, with added incentive due to the 1974 Arab oil embargo, geothermal energy has progressed rapidly. Today geothermal energy is probably the most successful of the DOE alternate energy technologies.

In the United States from 1960, when the first power plant at the Geysers was built, to 1978 a steady but small rate of increase occurred (Figure 1). Within four years after the Arab oil embargo, a significant increase occurred. The rate of increase since 1978 has been approximately $141 / 2 \%$ per year. Today over 2,000 megawatts are produced in the

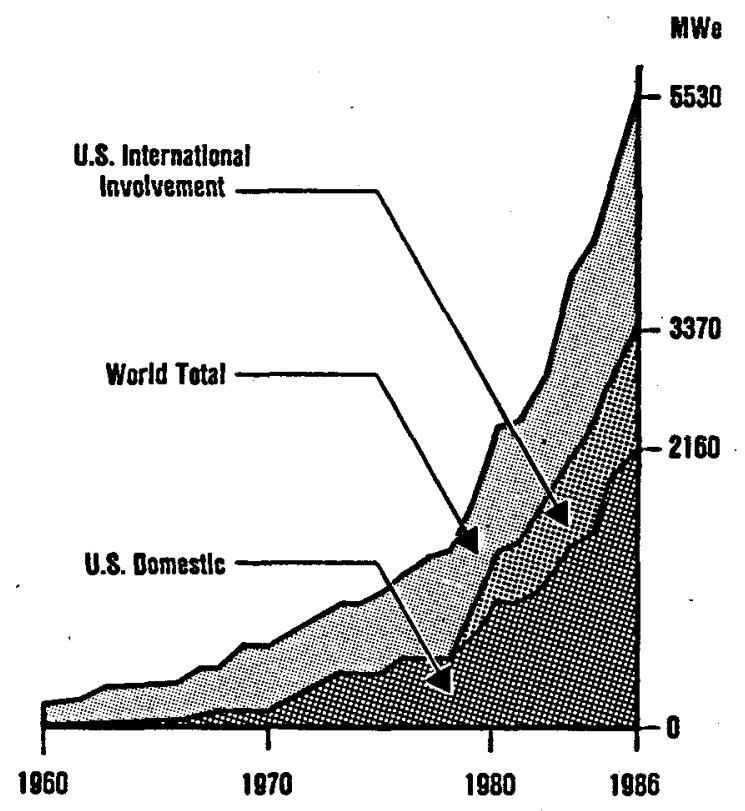

Figure 1. Growth of Geothermal Electric Capacity.
United States, and over 3,000 megawatts will be produced by 1990 . The projection for the year 2000 is 10,000 megawatts.

The worldwide development of power plants is increasing at a faster rate. Rapid increases have occurred since 1978 in Mexico, New Zealand, Italy, the Philippines, Indonesia, China, Japan and Central America.

I will now discuss how geothermal resources are created. At the mid-ocean ridges are the largest chain of mountains on earth. These mountains are all under water. The chain runs around the world, and at these points the crust of the earth is thin. Molten magma from the mantle of the earth rises into the crust, and two things may happen (Figure 2). If molten magma penetrates the surface, a volcano forms. Iceland is situated on the mid Atlantic ridge and was formed this way. Other mantle material cools as it rises and spreads out into plates, which can extend for thousands of kilometers. The rock shrinks as it cools; shrinkage cracks appear, and the plates start to diverge at rates of a few centimeters per year. As the cracks form, additional mantle rises and the process continues.

When the ocean plates move towards and collide with the continental plates, (Figure 3 ) two things happen. The ocean plates are heavier than the continental plates, therefore they pass or attempt to pass underneath the continental plates. As they go further into the earth, the rock starts to warm up again. The heat from friction, which occurs at the interface between the oceanic and continental crusts, causes melting and the basalt rises towards the surface. If magma penetrates the surface, a volcano forms. Frequently, the magma will be trapped in the earth, forming magma intrusions at depths between seven and fifteen kilometers. These intrusions act as point heat sources. If the intrusion is close enough to the surface, we can actually drill into it; maximum depth would be about 10 kilometers. If the rock above the intrusion is of sufficient thermal conductivity and properly insulated, we may have a hot dry rock source; if the magma intrusion is in conjunction with an aquafer, we may have a hydrothermal source.

There are temperature gradients around the United States, which may be large enough to economically justify the development of hot dry rock. The typical thermal gradient in the 


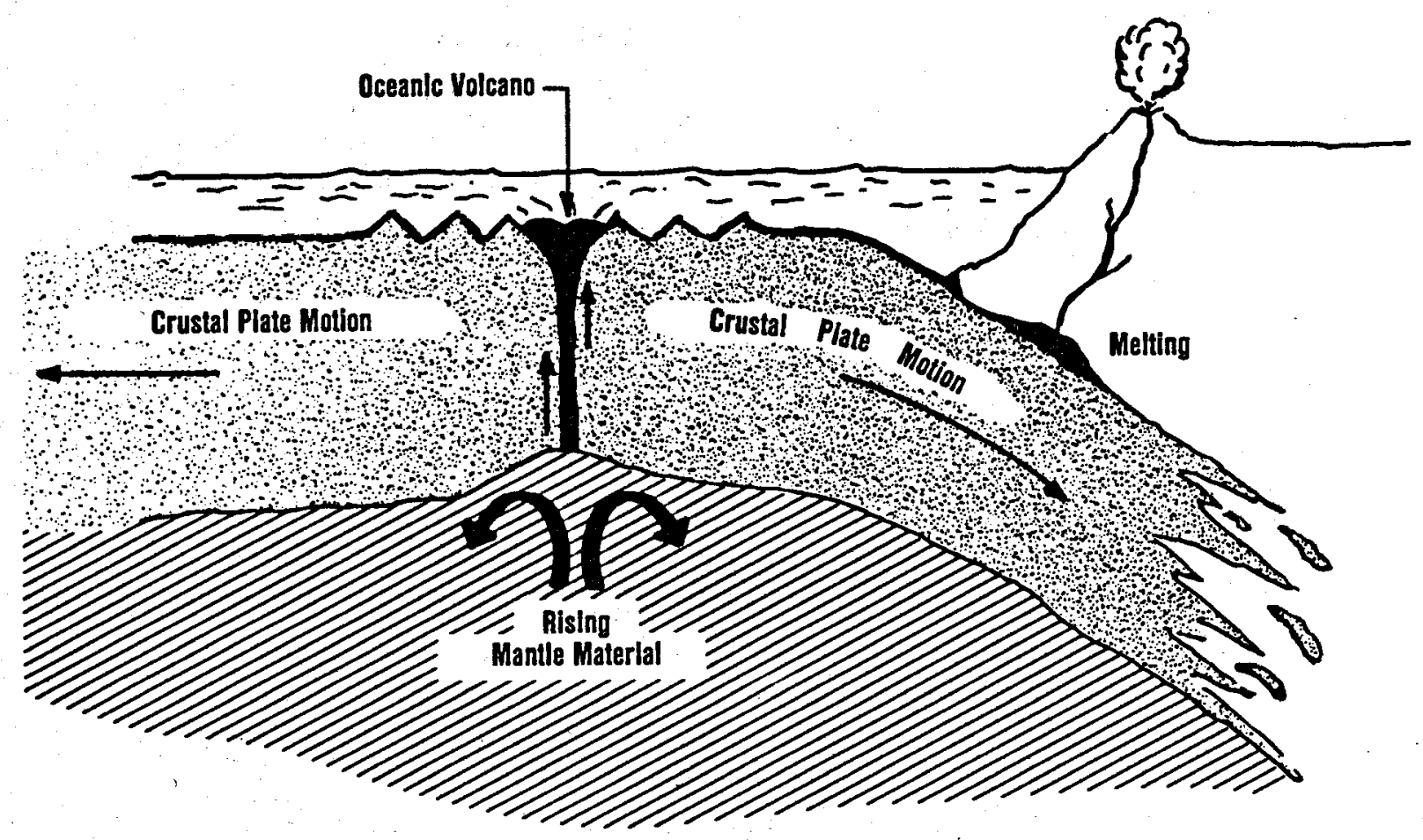

Figure 2. Plate Tectonics-Ocean Floor Spreading.

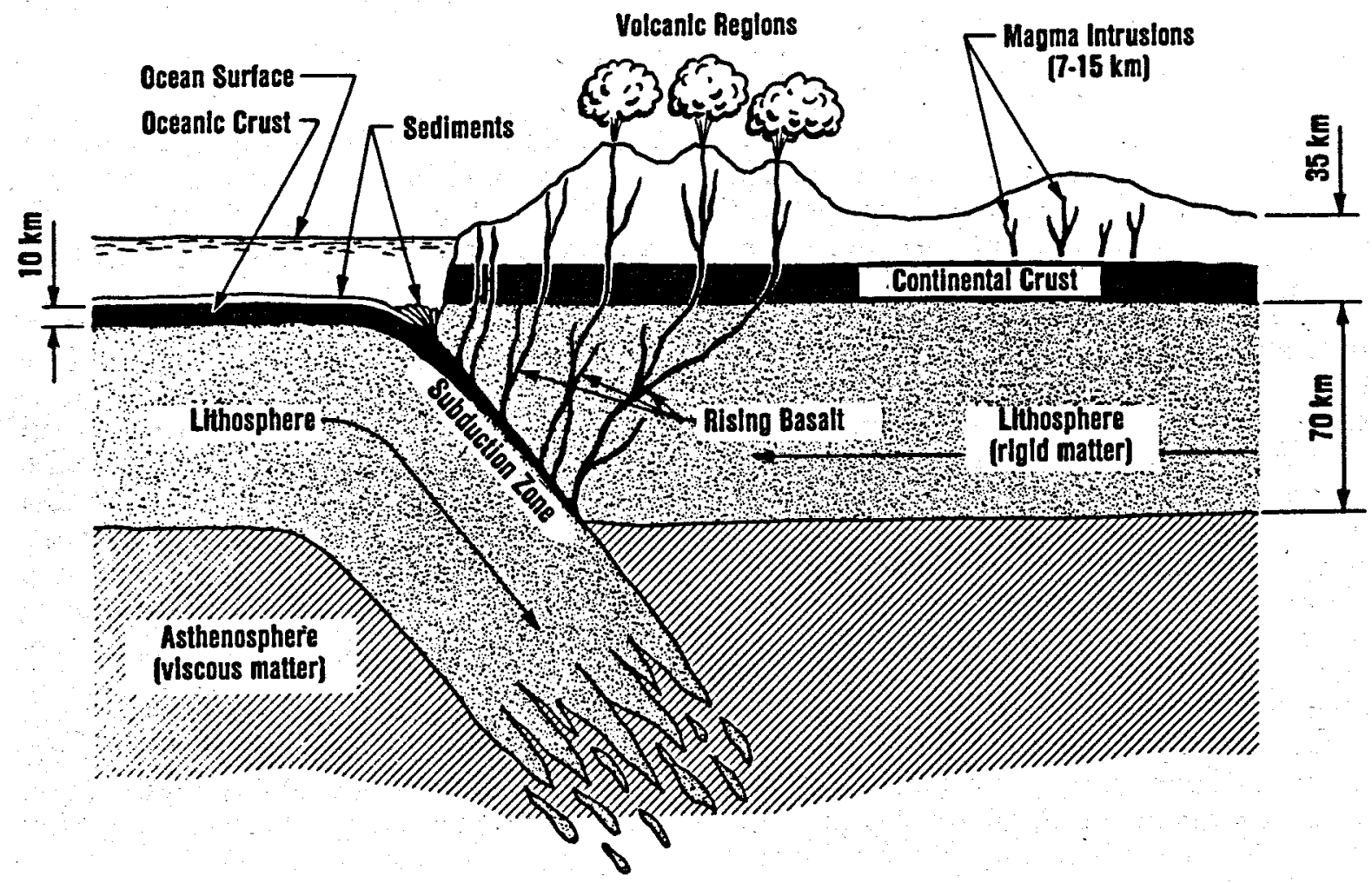

Figure 3. Plate Tectonics. 


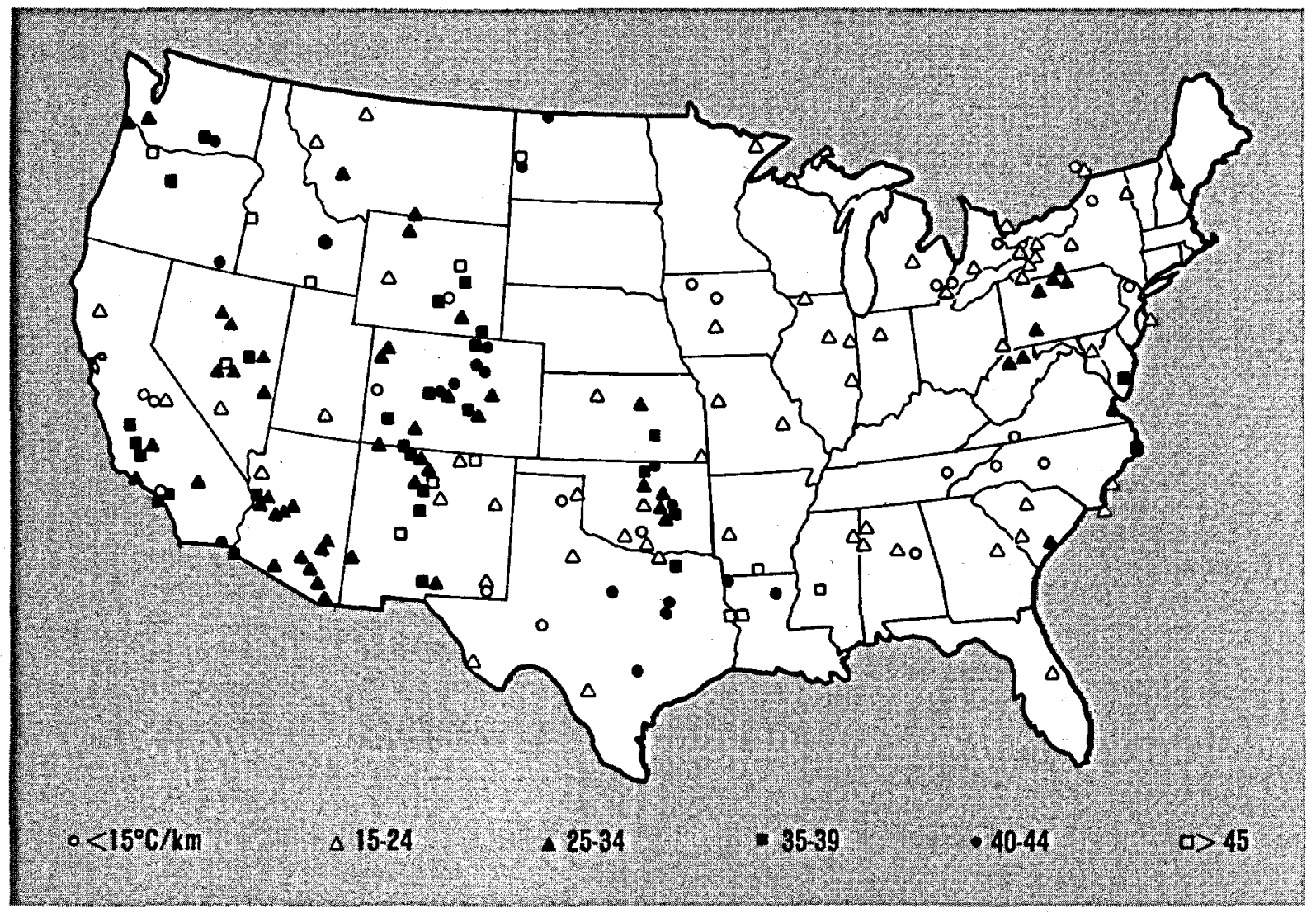

Figure 4. Temperature Gradient Map of the United States.

earth is between $15^{\circ}$ and $18^{\circ} \mathrm{C}$ per kilometer, but as shown in Figure 4, along the east coast in New Hampshire and the Delmarva Peninsula of Maryland, very old cooled magma bodies containing abnormal amounts of radioactive material exist. The heat released during the decay of these elements is sufficient to keep temperatures above the normal gradient. On the Delmarva Peninsula, temperatures of about $150^{\circ} \mathrm{C}$ were discovered at shallow depths.

Other potential sites for hot dry rock are along the Rocky Mountain range and the west coast of the United States. Los Alamos National Laboratory is undertaking hot dry rock research, and they are drilling into an extinct volcano. There they have temperature gradients of about $70^{\circ} \mathrm{C}$ per kilometer.

The following is needed for a hydrothermal source: a magma intrusion, which is the heat source; crystalline rock for thermal conductivity; a porous media, which acts as the reservoir; a method for fluid to get into the porous media, and a layer of impermeable cap rock to prevent the liquid and vapor from escaping (Figure 5). This type of reservoir is economically developed today. We either drill directly into the resource or into some fissures, which extend from it.

As shown in Figure 6, geothermal regions are associated with the mid ocean rifts in the Atlantic Ocean and around the Pacific Basin. Geothermal activity is present along the west coast of North America, Central America, South America, through southern Europe, the East Coast of Africa, New Zealand, Indonesia, the Philippines, Japan and the Kamchatka Peninsula of the Soviet Union. Today's operating geothermal power plants are along these geological faults.

I have categorized the four types of geothermal resources (Figure 7). Hydrothermal, as the easiest source to exploit, is used today in the United States, and in estimation about 1400 quads are economically recoverable. In 1985 , energy consumption in the United States was about $\mathbf{7 5}$ quads. Therefore, the United States 
would have about nineteen years of energy supply if all the hydrothermal resources were developed.

To exploit a geopressured source, we have to drill much deeper. Typically, the wells are about twice the depth of 2 hydrothermal well. Also, the pressures are in excess of twelve thousand PSI, rather than a thousand PSI. As a result, drilling costs are much more expensive. It has been estimated that there might be 1600 quads of heat and $\mathbf{2 8 0 0}$ quads of methane recoverable, but perhaps not economically. The energy available from these two sources is enough for sixty years.

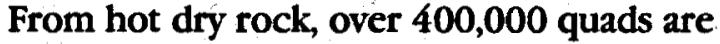
accessible, but not all of it will be economically recoverable. If it were, this would represent the energy requirements for 5,000 years. Magma will be even more difficult to exploit, but up to 500,000 quads are accessible.

DOE's highest priority is hot dry rock; second is the geopressure; third is hydrothermal and fourth is the magma energy, which is the longest term, highest risk item. DOE's research and development funds are allocated in this order.

Energy is extracted from hydrothermal sources by drilling wells into the reservoir. These wells are drilled and completed using the same materials and techniques used in oil and gas wells for the following reason. Approximately 80 thousand oil and gas wells are drilled a year in the United States compared to 80 to 100 geothermal wells. As a result, the companies involved in developing materials and drilling techniques will use their research and development money for the oil and gas

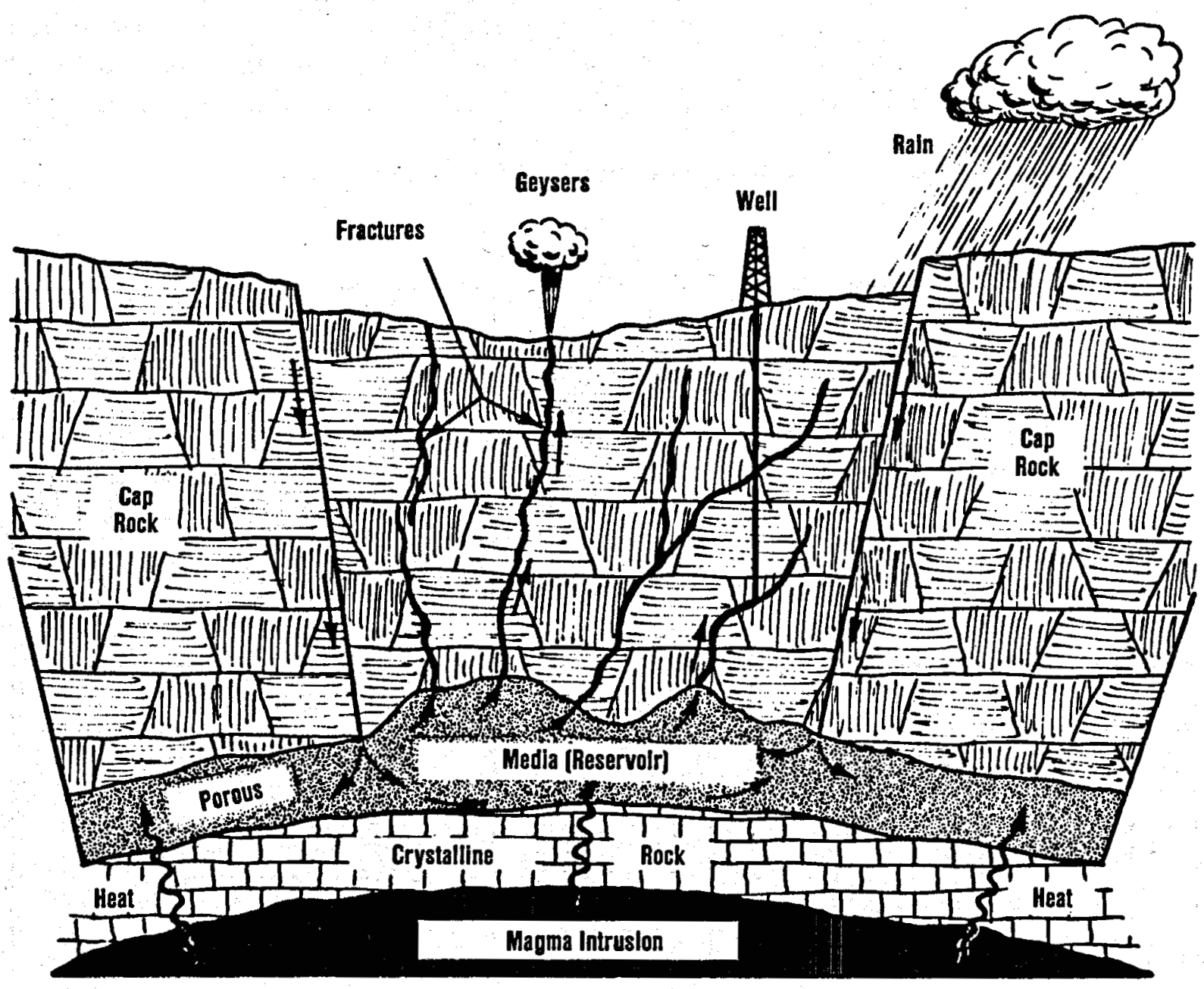

Figure 5. Major Elements of a Hydrothermal Geothermal Reservoir. 


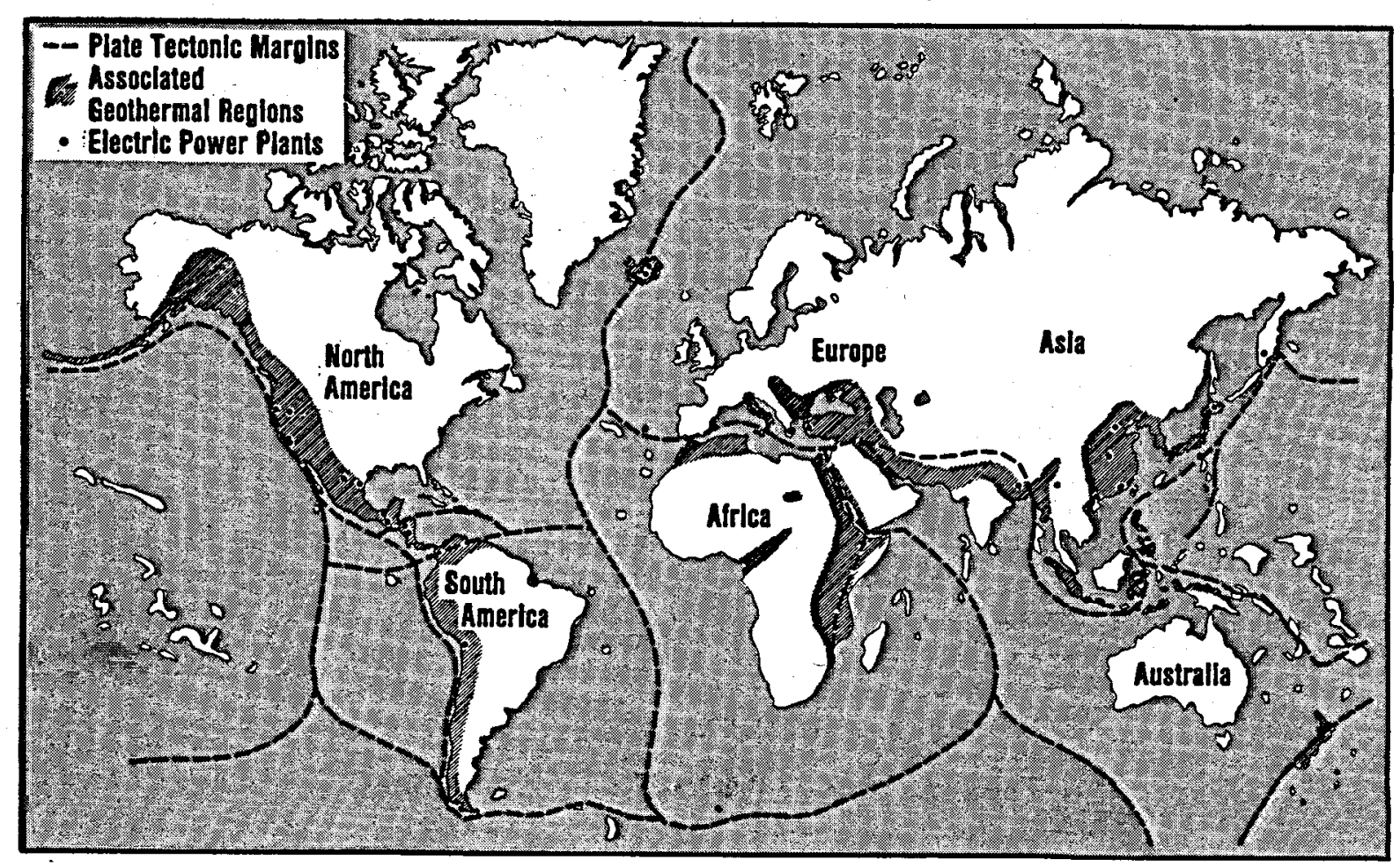

Figure 6. World Wide Locations of Major Geothermal Systems. to

\begin{tabular}{|c|}
\hline Hydrothermal \\
\hline \\
- Easlest to Explolt \\
$-\sim 1,400$ Quads Economically Recoverable \\
\end{tabular}

No Indigenous Porosity or Llquid

\begin{tabular}{|c|}
\hline Hot Ory Rock \\
\hline \\
- Greater Oepth and Harder Rock \\
- Up to 430,000 Quads Accessible \\
- Economics Uncertain \\
\hline
\end{tabular}
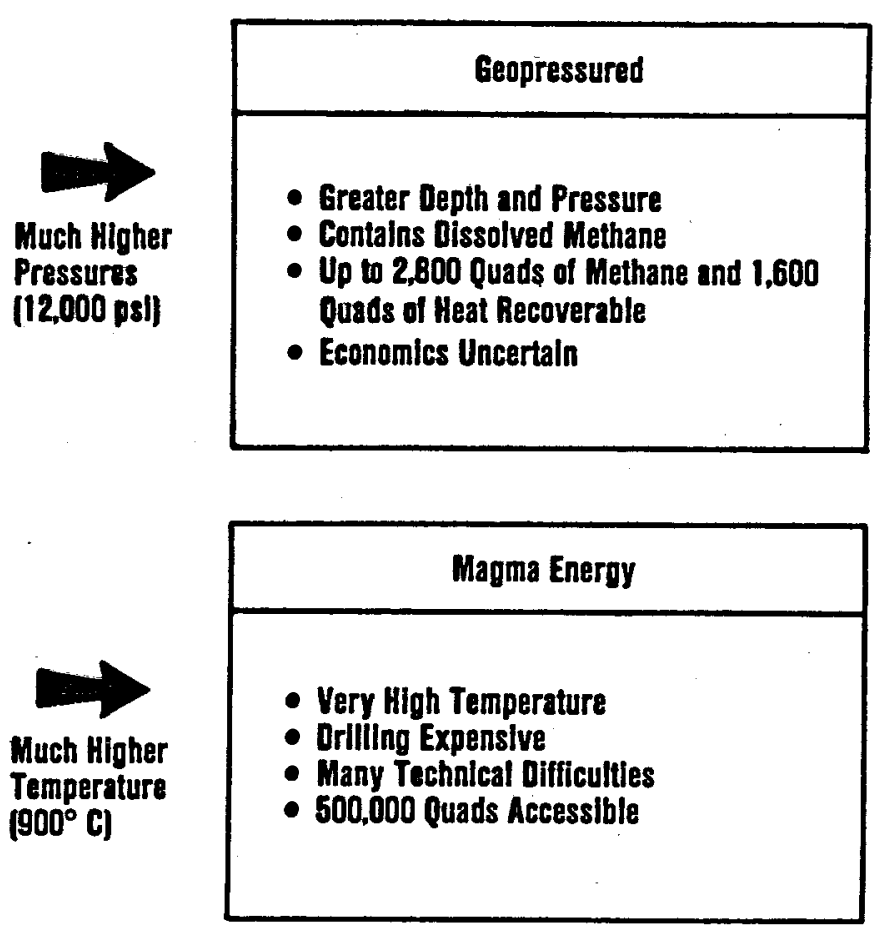

Figure 7. Geothermal Resource Types. 
industry. Since industry will not invest their funds to develop materials for the specialized needs of the small geothermal industry, DOE has decided to support this effort. Regardless, the geothermal wells are similar to oil and gas wells with a few exceptions. In geothermal, the drilling takes place in rock where temperature may be $300^{\circ} \mathrm{C}$. This rock is much harder than rock encountered in oil and gas exploration. As a result, the drill bit materials last for shorter periods, and because the rock is also more brittle, it is more susceptible to fracturing, which can lead to lost-circulation problems.

A geothermal well is a cased hole (Figure 8). It is stepped at various points, depending upon the problems encountered during the drilling operation. Also, as the hole gets deeper, the bore diameter must be reduced because of the heavy load on the drill rig. The cost of a drill rig varies between about $\$ 10,000$ and $\$ 20,000$ per day; it takes between 20 to 90 days to drill a well. Due to the cost, speed is of the importance.

As the hole is drilled, a drilling fluid, generally consisting of a bentonite-water slurry, is circulated. Bentonite is 60 to $70 \mathrm{wt} \%$ sodium montmorillonite and $\mathbf{4 0}$ to $30 \mathrm{wt} \%$ calcium montmorillonite. The drilling fluid cools the drill bit, removes the cuttings from the hole, and prevents the hole from collapsing. The casing is lowered in immmediately behind the advancing drill bit to also prevent the hole from collapsing. If the drilling process is stopped at anytime to remove the drill bit, all of the casing must be pulled out. This is a time-consuming and therefore, expensive procedure.

After the well is drilled to the top of the reservoir, and the casing installed, cement is pumped into the well to fill the annulus betwcen the casing and the rock formation. After the cement hardens (generally within 24 hours), drilling continues into the reservoir. From this point down, the hole may be uncased or a slotted liner may be put in. If the latter is done, it is not cemented.

The cement gives structural stability to the hole, imparts corrosion resistance by preventing ground water and geothermal brine from contacting the outside of the casing, and prevents fluid escaping up the outside of the casing. The latter is called a blow out, which is difficult to control and can lead to the abandonment of a well.
The materials problems that exist in geothermal wells are: corrosion of the casing, deterioration of the cements, decomposition of the sealing materials used in the drilling operation, and high temperature tools. The net result of these difficulties is that a geothermal well costs about four to five times more than oil or gas wells. A barrel of oil is also worth considerably more than a barrel of hot water.

There are three types of processes for converting heat from the earth to electricity. The simpliest to exploit is the dry steam process, where super heated steam comes from the ground, as it does at the Geysers field, located north of San Francisco. A fifty megawatt plant has about a million pounds per hour of steam, at about $180^{\circ} \mathrm{C}$ going into the power plant (Figure 9). The steam goes directly to 2 turbine after which non-condensible gases, such as carbon dioxide and hydrogen sulfide, are removed. These are passed through an $\mathrm{H}_{2} \mathrm{~S}$ removal system, where at normal plant operating conditions, approximately 100 pounds per hour of sulfur is produced.

A sludge rich in arsenic and vanadium is produced as a by-product of the $\mathrm{H}_{2} \mathrm{~S}$ removal process. In our bio-chemical program we are

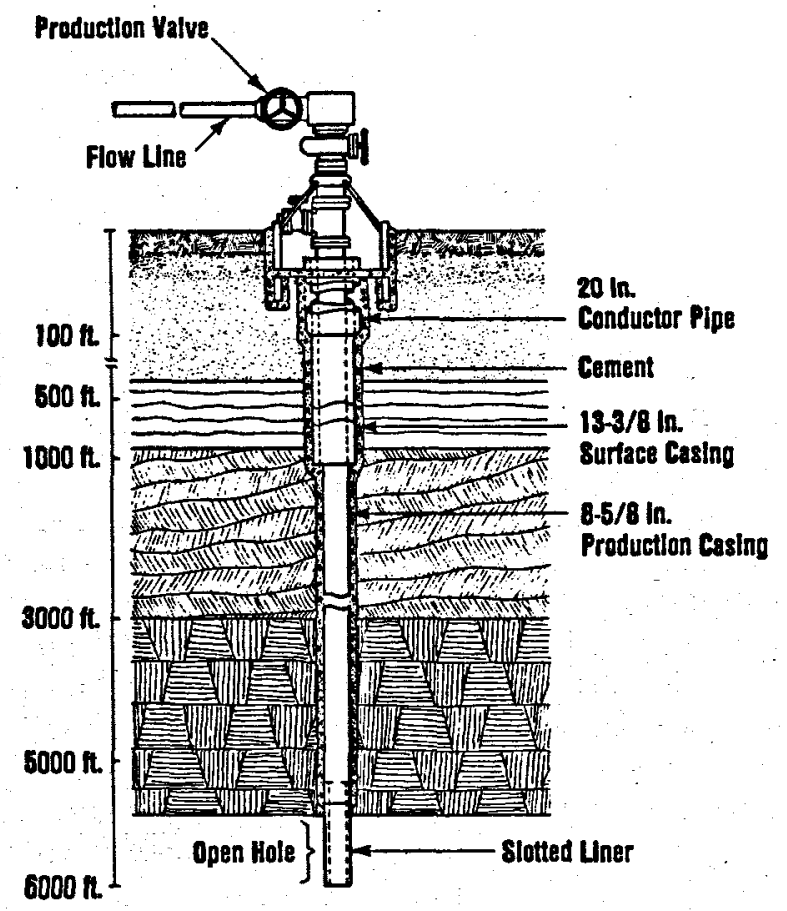

Figure 8. Major Components of a Geothermal Well. 
trying to detoxify this waste by using microorganisms, which I will discuss later.

The remaining steam travels to a condenser, where it is cooled and reinjected into the formation in order to extend the life of the reservoir.

Unfortunately, the dry steam reservoirs are few in nature. To my knowledge, there are only three dry steam reservoirs in existence; one in Larderello, Italy, another at the Geysers, and another at Yellowstone National Park, where there will be no attempt to produce electricity.

The larger part of the hydrothermal resource is hot water, and for high temperature reservoirs, this often necessitates the utilization of hypersaline brines. For a 50 megawatt plant, there is approximately $3,000,000$ pounds per hour of brine at a salt concentration of 300,000 parts per million of total dissolved solids and a pressure of about 600 PSI going into the steam separator (Figure 10). There the brine is flashed to yield approximately 600,000 pounds per hour of steam, which goes to the high pressure end of the turbine. The unflashed brine travels to a second flasher, which produces 350,000 pounds per hour of steam for the low pressure side.

At the discharge from this second stage flasher, we have a brine stream, which is almost 500,000 parts per million of dissolved solids. This stream goes to a clarifier where further salt concentration occurs. Salts remaining in solution are pumped to a reinjection well. Others are discharged from the clarifier as a solid residue, which for a 50 megawatt plant, represents about 5,000 pounds per hour of $65 \%$ solid sludge. This sludge contains almost every element from the periodic table. The sludge may be classified as a toxic material, which we are trying to detoxify and use as a source of valuable metals.

The final power cycle is called a binary cycle (Figure 11). Below $150^{\circ} \mathrm{C}$ it is not economically attractive to flash the brine for direct use in a turbine. The heat must be transferred from the brine to a low boiling point organic, which can be used as the working fluid for the turbine. A frequently used organic is a $90 \%$ isobutane, $10 \%$ isopentane mixture. As the brine temperatures decrease, it is necessary to increase the flow rate. For this process about seven to eight million pounds per hour of brine and nearly the same mass flow for the organic

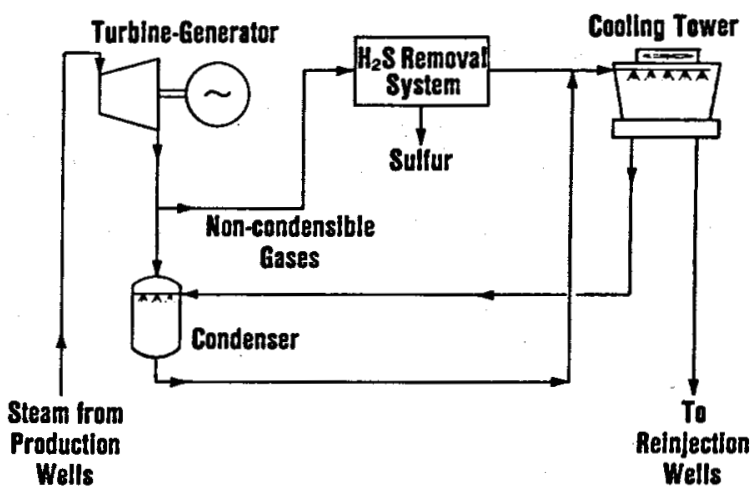

Figure 9. Dry-Steam Geothermal Power Plant.

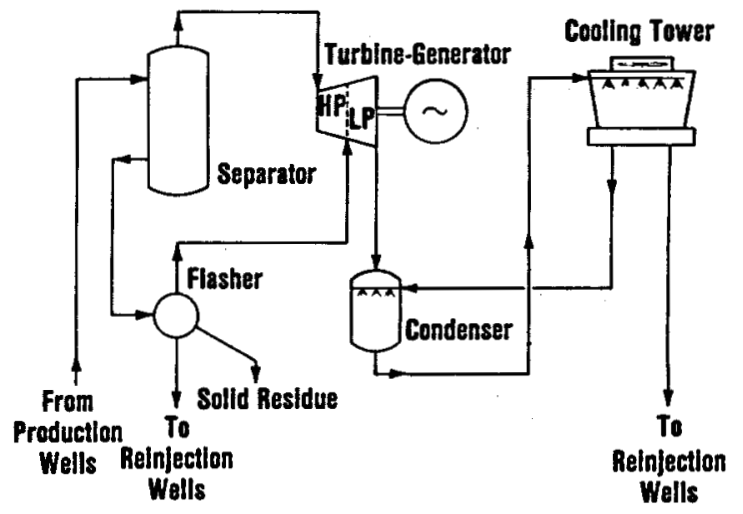

Figure 10. Separated-Steam/Hot-Water Flash Geothermal Power Plant.

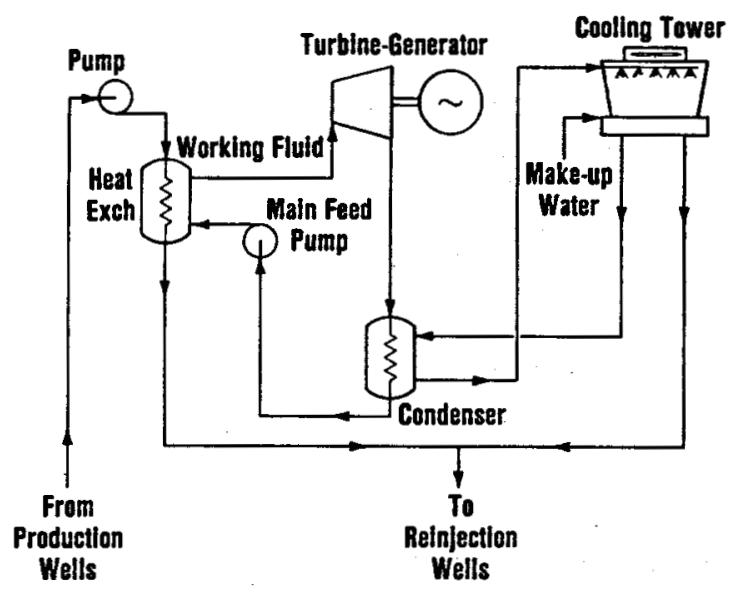

Figure 11. Binary Geothermal Power Plant. 


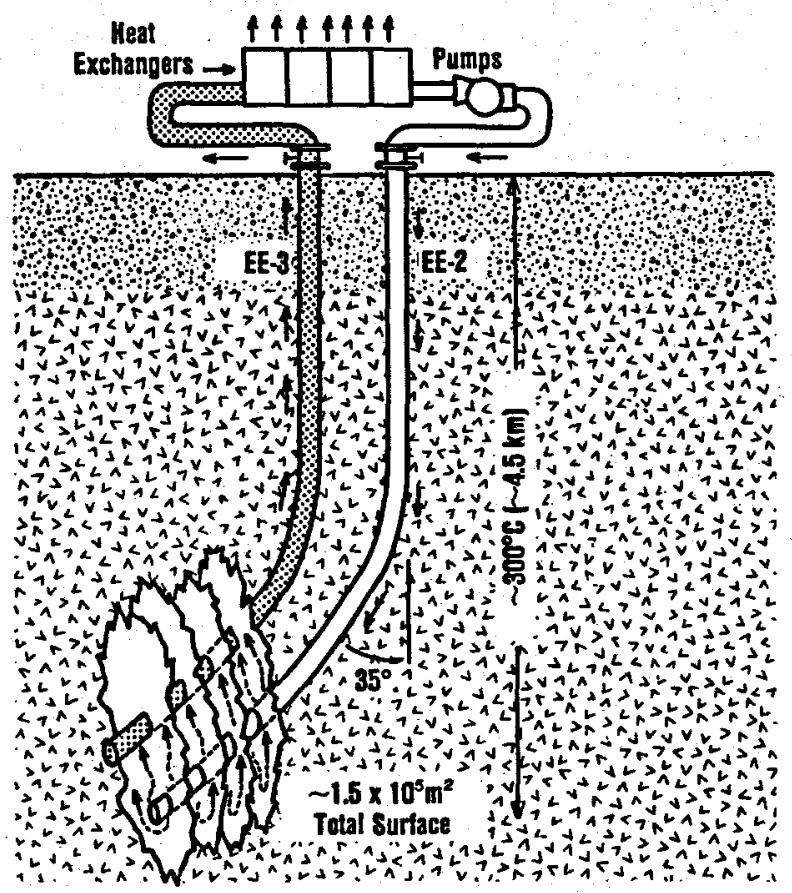

Figure 12. Energy Extraction From Hot Dry Rocks.

mixture is required for a $50 \mathrm{MWE}$ plant. The highest cost item in this plant is the heat exchanger, which represents about $30 \%$ of the total capital investment in the plant. High alloy steels are used because of the thin-walled tubes, which are needed to give adequate heat transfer. We are trying to develop a nonmetallic heat transfer tube for use as a replacement for the high alloy steel.

One advantage of a binary process is that since the fluid is pumped, it is kept under pressure. This prevents flashing, which would result in the formation of scale. Therefore, there is no solid waste produced in this process.

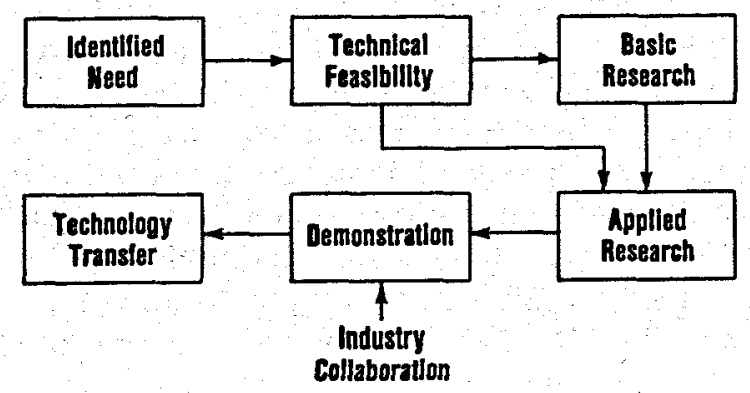

Figure 13. Materials Development Flow Chart.
The utilization of hot dry rock as a geothermal source is a simple concept. Two wells are drilled. The first well is drilled to a depth at which the desired temperature is obtained. The system depicted in Figure 12 was built at Los Alamos National Laboratory, where $300^{\circ} \mathrm{C}$ was attained at a depth of 14 to 15 thousand feet. A second well was drilled to a point above the first well, and then the rock between the two wells was hydraulically fractured. This fractured area represents the heat transfer surface. Cold water is pumped through the fractures, becomes warm and circulates to the surface, where heat is extracted. This system could be used anywhere in the country; it is just a question of how deep one can drill economically.

The Los Alamos system was sized to produce about 10 megawatts thermal. A thirty day run was recently completed. The questions which needed answers were the temperature at which this would stabilize, and what would be the water losses since some water will be lost into the formation and will not find its way to the production well. As this system was tested, the temperatures increased, probably due to the additional fracturing of rock as a result of thermal stresses. Also, water losses were reduced. At the end of the thirty day test period, the water losses were down to about $10 \%$, which was encouraging. Next, a binary cycle will be hooked to the heat exchanger and approximately two megawatts of power will be produced. This system will then be run for long periods to determine its economic feasibility.

There are problems with materials that have been encountered in this program: concerns about the cements; problems with high temperature cable seals and packers used in the hydraulic fracturing.

I will now outline the materials program. As I mentioned earlier, we have a materials program because the DOE feels that industry will not support the long term, high risk $R \& D$ that is needed to develop geothermal energy at the rate DOE would like to see it developed.

The first part of our materials program involves identifying the need (Figure 13). We accomplish this through industrial advisory panels; we depend upon professional societies, such as the American Petroleum Institute, ASTM and the National Association of Corrosion Engineers (NACE). We also have our own 
input and DOE's input. We then try to determine how feasible it is to solve these problems.

An example of a program we determined feasible was the biochemical separation of waste. About a year ago, we developed an idea that we thought would be applicable to geothermal resources, and our first step was to determine its technical feasibility. With sludge obtained from a geothermal company, we performed preliminary kinetic experiments. Our MIT practice school graduate students developed a flow sheet and made a preliminary cost estimate. At this point, we felt that the process was technically and economically feasible. Therefore, it was decided to continue with a basic research program.

Our work with cement is another example of a basic research program. We want to develop carbon dioxide resistant cements because some of the aquifers we drill through have high carbon dioxide contents. It is well known that carbon dioxide reacts with cements to form calcium carbonate. This reaction is called carbonation and can be damaging to cements. Therefore, our first step was to determine the effects of temperature on the mechanism. Thus far, we are going through a basic research mode, and later we will use these results in our applied research.

Elastomers are another case where we have gone from technical feasibility to applied research. We have probably developed the best high temperature elastomer for static seals available for use by the geothermal, oil and gas industries. We now want to optimize the material composition for use in rotary seals.

We continue our development method with a demonstration mode, which involves field testing. There are not two geothermal fluids the same, and it is difficult to simulate geothermal fluids in the laboratory. The best test method is to go to a field site, where we perform experiments in collaboration with industry. Working at a field site also develops the industry's interest and enhances our technology transfer.

We are currently working on high temperature well completion materials. We want to develop a lightweight cement with a density of 1 to 1.1 grams per cc. We need a lightweight material to reduce the pressures that are needed to pump the cement into the well. Reducing the pressure requirements will reduce the probability of fracturing the rock, which results in a lost-circulation problem. We need materials that are temperature stable and are resistant to brine. Presently, we are working on $300^{\circ} \mathrm{C}$ materials, but our goal is $500^{\circ}$ to $600^{\circ} \mathrm{C}$, because these temperatures will be encountered as we start to drill close to magma bodies.

As part of the basic research phase of this program, we are studying the interfaces between cements and lightweight fillers, which are generally glass. We are doing surface science measurements using most of the state of the art techniques to study this interface. We want to improve this bond. We are also doing similar work with lost-circulation control materials. These are the materials that are pumped into the well to plug any fissures that cause lostcirculation problems. Bentonite water mixes are normally used for the drilling fluids, and we would like to add something to the drilling fluid to convert it into a highly viscous material, which would cure rapidly, hopefully with a net expansion, in order to fill up these fissures. We are studying interactions between magnesium oxide and ammonium polyphosphate with bentonite for this purpose.

Furthermore, we are studying interactions between glass beads, oil well cements and bentonite. Our goal is to produce materials where we can control the setting times at high temperatures, which will give us high strength and low permeability at low cost.

Up to about five years ago, the best high temperature elastomer available had an operating temperature range of about $200^{\circ} \mathrm{C}$, which is very high for the oil and gas industry. When $300^{\circ} \mathrm{C}$ was reached, these materials fell apart very quickly. As part of our program, we have developed a material that will give very long service life at $260^{\circ} \mathrm{C}$. Our material has also been used for short periods of days and weeks at temperatures as high as about $315^{\circ} \mathrm{C}$. This material is produced now by at least three companies in the United States. It is also beginning to be used in nuclear power plants, and in many other applications where hydrothermal stability at a temperature of $300^{\circ} \mathrm{C}$ is needed. We are trying to use this material now for rotary seals. We can reduce the temperature capabilities to $200^{\circ} \mathrm{C}$, but we want to improve properties, such as tear resistance, toughness and lubricity. 
We also want to develop these materials for use as corrosion resistant liners on well casing and collection pipes. At the moment we are studying ways of bonding the elastomer to steel. As part of this study, we have a program looking into various chemical coupling agents that we might be able to use.

We have another program to determine the effects of brine contamination of binary fluids on the corrosion rates of metals. The binary fluid is benign as long as it is clean, but once any oxygen, water or chlorides are added, the corrosion rates may change markedly.

One of our other programs is on nonmetallic heat exchanger tubing. Using our concrete polymer technology, we incorporate fillers having high thermal conductivities to make a thin-walled plastic heat exchanger tube. We have obtained thermal conductivities approximate to those of stainless steels. We would like to obtain thermal conductivities of carbon steel, but stainless steel might be adequate.

At the moment we are trying to determine the wall thickness needed to withstand the process requirements. In the shell and tube heat exchanger, the brine flows through the tube, under a pressure about 200 PSI. The organic fluid is on the shell side where the pressure is about $600 \mathrm{PSI}$. We need a tube that will withstand an external force of about $\mathbf{4 0 0}$ PSI at $150^{\circ} \mathrm{C}$, and we have made materials to meet this requirement. Once we optimize the wall thickness, we will build larger tubes, which we will then test in a prototype heat exchanger.

Now, with regard to the biochemical separation of waste, geothermal fluids contain a variety of elements. Because no two brine sludges are the same, we work with as many wastes as possible. Figure 14 gives the composition of one fluid, which contains large amounts of titanium, vanadium, manganese, strontium and rubidium. Other wastes have high concentrations of copper, chromium and arsenic. In order for the waste to be disposed of in a conventional landfill, two criteria must be met. One criterion is called the total threshold limit concentration (TTLC), which is the total amount of the particular element per unit mass of the waste form. If any of the TTLC given in Figure 14 are equaled or exceeded, the waste has to be classified as a toxic material.
The other criterion is called the soluble threshold limit concentration (STLC), which is the amount of the material that can be leached out. In this test, the waste in its final form must be ground to no greater than two millimeters. The waste is then exposed to a sodium citrate solution at a pH5 for 48 hours. The concentration of the leachate is measured, and if any of the STLC numbers are exceeded, the waste is classified as toxic (Figure 14). For a 50 megawatt plant, the disposal of a toxic waste can cost about a million dollars per year. There is a big economic incentive in detoxifying the waste, and since many of these materials have economical value, if they are recovered, they may be sold. They are also strategically important.

We are trying to treat the solid residues with micro-organisms to detoxify the waste. If we can put it into a soluble form by converting the insoluble metal sulfides to soluble sulphates, we then have two options; one option is to reinject the waste solution back into the formation, and the other option is bioaccumulate the metals and then separate them by using biochemical or conventional mineral extraction techniques.

As far as the bioleaching is concerned, we found that mixed cultures of Thiobacillus thiooxidans and Thiobaccilus ferroxidans seem to

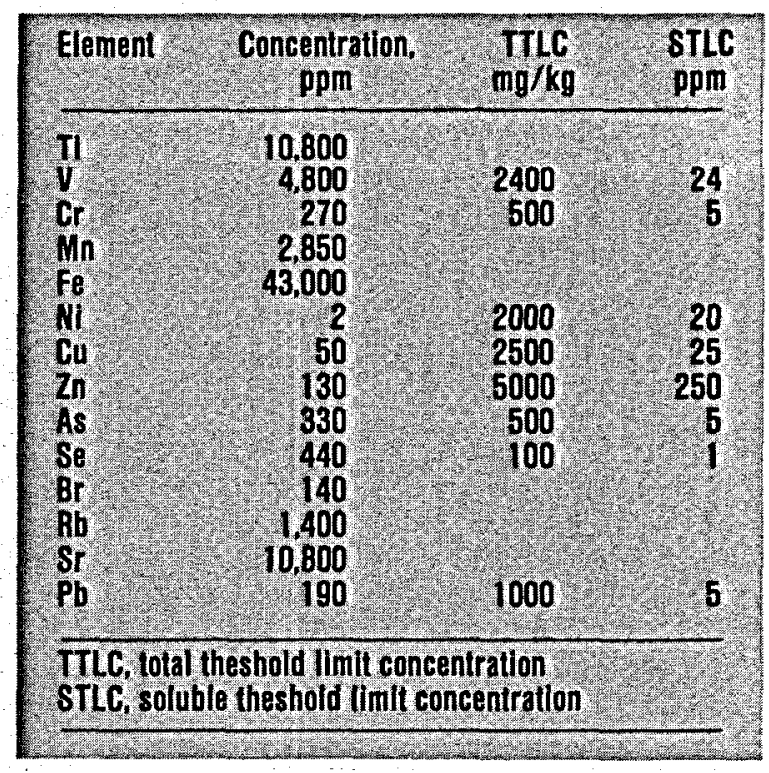

Figure 14. A Typical Composition of Geothermal Waste Residue. 
give us very high leach rates. They are very site specific, therefore, we can selectively choose which element or groups of elements we want to recover.

As far as the bioaccumulation, we find that mixtures of $E$. coli seem to be very effective. We have done cost estimates for the bioleaching and for the bioaccumulation processes and both seem to have great economic potential. Now we want to develop a much broader program with DOE/Basic Energy Sciences, the military, and in addition, more applied parts of DOE like geothermal and fossil energy to try to develop a broadly based research program, which will encompass basic research, applied research and some engineering studies.

I would like to explain how sometimes luck plays a very important role in the types of research that we do. Up to about seven or eight years ago, we would never add portland cement to polymer concrete as a filler material. Our concern was that in the presence of moisture, the portland cement would hydrate, probably resulting in shrinkage, which would give us cracks, and therefore, reduce the durability of the material.

In the early 1980's, we made some samples, which we sent out to the Geysers, and these samples were exposed to steam at the top of a well at about $260^{\circ} \mathrm{C}$ for approximately a year. They were all made with the same monomer system. At the end of a year, some samples disappeared. Some samples severely deteriorated, and four were in a very fine condition (Figure 15). Our curiosity was aroused. We discovered that we had put some portland cement into these four samples.

Next, we started looking at the constituents of portland cement. Portland cement is a mixture of many materials, such as silicon dioxide,

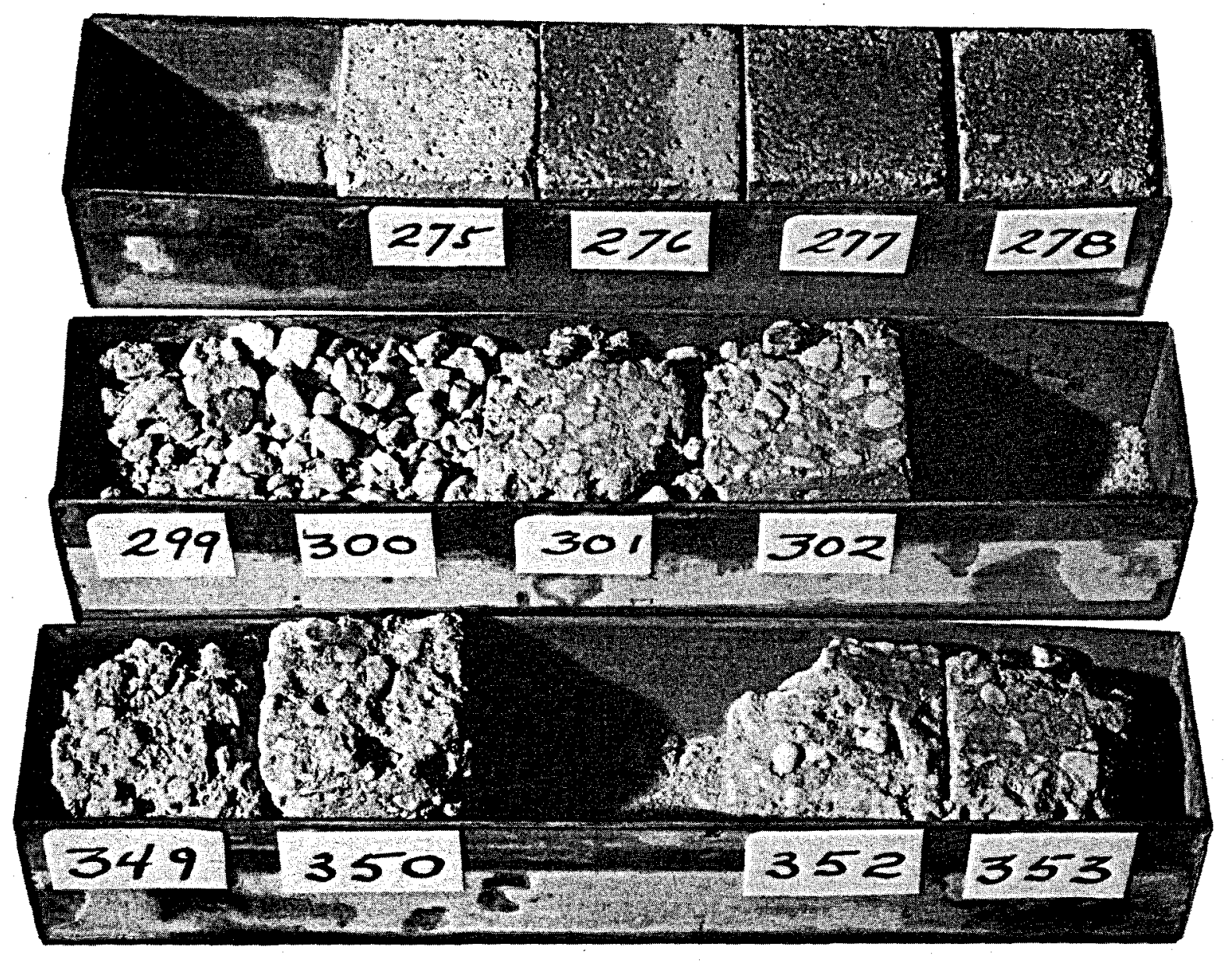

Figure 15. Polymer Concrete Formulations After Exposure to Geothermal Fluid. 
iron oxide, aluminum oxide, and it also has calcium containing compounds. In this series of experiments, we took methyl methacrylate and mixed it with various amounts of each portland cement constituent as a filler material. We measured the weight loss after thirty days at a temperature of about $238^{\circ} \mathrm{C}$. As illustrated in Figure 16, we discovered some very significant effects resulting from the calcium containing compounds, and we felt that it was from the calcium. Certainly calcium hydroxide or calcium oxide would not be added to a polymer concrete that was going to be exposed to a hydrothermal environment, because these materials are soluble. Portland cement has insoluble forms of calcium, such as dicalcium silicate and tricalcium silicate, which we felt were probably causing the beneficial effect.

We made up some samples again with methyl methacrylate, which melts at about $100^{\circ} \mathrm{C}$. We added sand, cement and dicalcium silicate and exposed these samples for about a month in a 250,000 parts per million brine solution at $238^{\circ} \mathrm{C}$. Considerable enhancement in the durability of these samples was attained as we increased the concentration of the insoluable form of calcium.

We then started a study to determine the mechanism, and we found that in the presence of water, the calcium compounds in portland cement release divalent calcium ions $\left(\mathrm{Ca}^{++}\right)$. These interact with carboxylate ions (COO-) formed by the hydrolysis of carboxyl groups in the polymer chains, forming a cross linking. Therefore, we form a calcium polymer complex, a stable material, which is then coated with tobermorite, a hydration product of portland cement. This acts as a reinforcement. This material seems to give us good hydrothermal stability. We have patented it, and it is being used in many polymer concrete formulations, which will be used in hydrothermal environments.

This work has resulted in several other programs for us, such as rapid runway repair, where the materials have to work in wet environments.

Now, how have we applied this to our goethermal work? In steam separators, brine is introduced into a vessel; it expands and at the top of the vessel steam is withdrawn. At the bottom, unflashed brine is removed. We lined a prototype system with polymer concrete, and we ran a test of this unit in the Imperial Valley of California. The test was performed in conjunction with a unit, which was identical, except this unit did not have the polymer concrete liner.

This unit was susceptible to rapid scale accumulation. Before we ran the test, we tested a lined pipe for about 900 days; we found no scale accumulation on the wall of the pipe. We then build the steam separator, and tested it. It ran without any difficulty, compared to the rapid plugging that would have occurred in the more conventional vessel.

At the end of the test, we did have some scale accumulation but much less than the accumulations in the conventional vessel. Also, the scale was less well-bonded to the steel surface, making it easier to clean out. This material has subsequently been tested in other types of geothermal brines, and people have concluded that it has better corrosion resistance than Hastelloy in these particular fluids. Companies have expressed great interest in the potential for lining complete geothermal power plants with this formulation, and they may now be using the material.

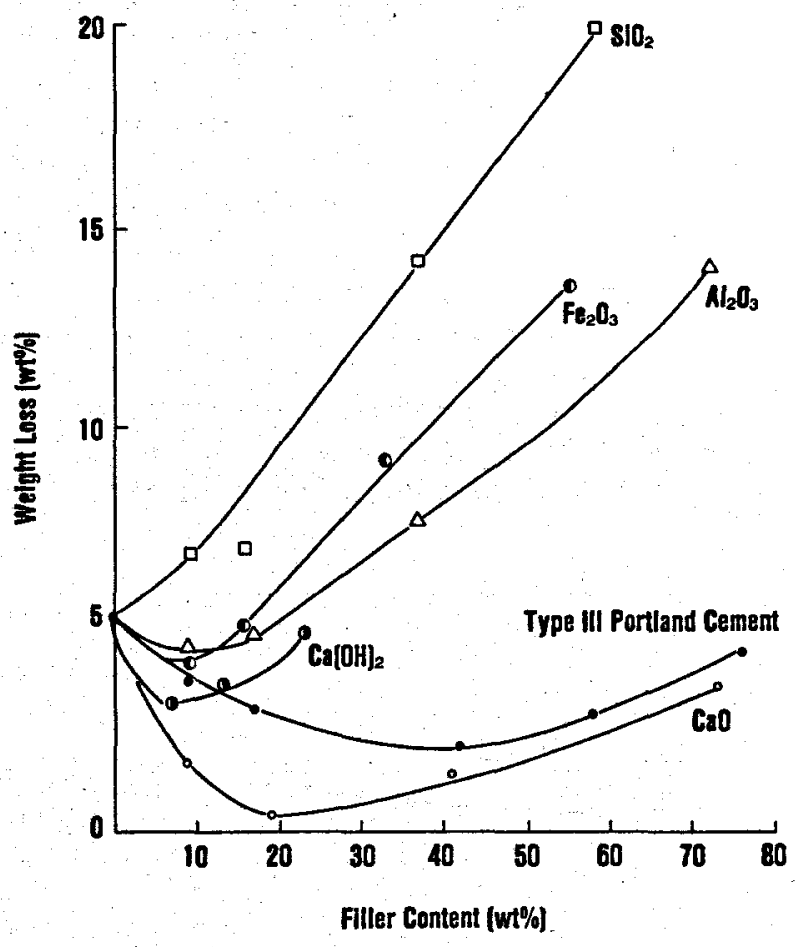

Figure 16. Effect of Type III Portland Cement and Chemical Constituents of Cement on Weight Loss. 
I will now discuss the cost of geothermal energy. Referring to Figure 17, the curves represent the fuel supply for a 50 megawatt power plant. The geothermal cost includes the cost of the well, the pumps and the collection pipes. Therefore, they represent the cost of hot water delivered to the plant. For well depths between 1 kilometer and $21 / 2$ kilometers and water temperatures as low as $150^{\circ} \mathrm{C}$, the cost varies from $\$ 1$ to $\$ 6$ per million BTU's.

For coal, at least in the areas where the geothermal activity exists, fuel costs range between $\$ 4$ to $\$ 8$ per million BTU's. In many cases the fuel increment for geothermal is less than that for coal and for other types of power.

The other advantage is that we can build geothermal plants in one megawatt modules, ten, fifty, or in units compatible with a utility's rate of growth; we can add them as demand requires. Also, much less time is needed to build the plant. A geothermal plant can be designed and built in three to four years.

The cost of electric power produced by a $250^{\circ} \mathrm{C}$ geothermal flash plant or a $200^{\circ} \mathrm{C}$ binary plant is compared in Figure 18 to those from nuclear, coal and oil. There is not a great difference in plant cost. The big difference is in the fuel cost. Based on 1982 dollars, the flash process produces electricity at three and a half to four cents per kilowatt hour. The binary plant costs are four and a half to five cents. Utilities using geothermal claim that it is their most cost effective method of producing electricity, other than hydropower. Geothermal is quite competitive with nuclear and coal, and geothermal causes much less environmental consequences.

To summarize, geothermal is a broadly based resource. The hydrothermal reservoirs in the United States are predominately on the west

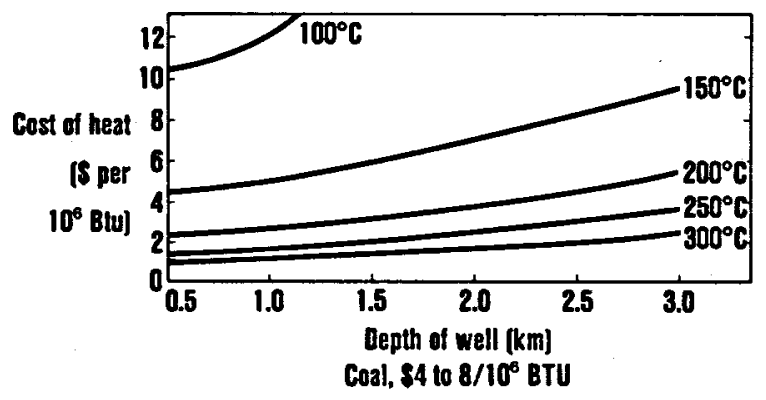

Figure 17. Cost of Geothermal Heat. coast. The geopressure areas are around the Texas and Louisiana shorelines, and hot dry rock would be available on the east coast as well as the west coast. Geothermal is clean and safe. Measurements to determine whether there is any increase in seismic activity as a result of the extraction and reinjection of these fluids have been made. No increases have been detected.

Geothermal is reliable. Plant operators claim that these plants run with availability factors greater than $95 \%$. The costs of geothermal are also coming down. One of the goals of DOE is to reduce the cost of drilling wells by $50 \%$ by the year 2000. If we can meet this goal, the costs will become even more competitive.

Geothermal is also a potential source of metals. Some of the earliest geothermal wells drilled in the United States were for mineral recovery. If we can develop these mineral recovery processes, the minerals may have a greater value than the electricity.

In the future, we hope to be working on castable well casing. The goal is to eliminate the metallic casing, thereby eliminating severe corrosion problems. We would also like to be able to apply this liner directly behind the drill bit as we drill. Therefore, we will need a low cost castable ceramic which can cure very rapidly in the hydrothermal environment.

We hope to extend our work with lightweight cements and lost-circulation control materials up to $500^{\circ} \mathrm{C}$ to $600^{\circ} \mathrm{C}$. We also want to find a way to convert a drilling fluid into a cement. We could drill the well and then add a substance to convert the drilling mud into a cement, which would eliminate another operation and reduce the cost.

These are some of our goals. Hopefully, we will see the continued improvement and development of geothermal energy.

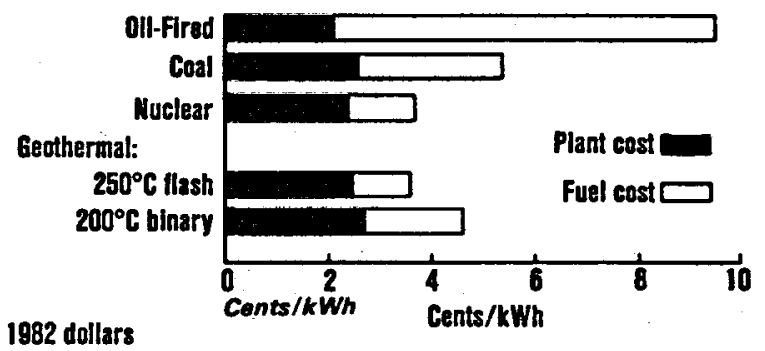

Figure 18. Comparative Costs of Producing Electricity. 


\section{ABOUT THE AUTHOR}

Lawrence E. Kukacka was born and raised on Long Island. He received a bachelor degree in Chemical Engineering from Clarkeson University in 1953.

After serving in the Army and working at Sylvania Electric Products in Hicksville, Long Island, Lawrence came to Brookhaven in 1956. His first work at Brookhaven involved the molten salt extraction of fission products from liquid metal coolants being considered for use in nuclear reactors. He then worked in developing cobalt 60 gamma radiation chemical processes for a variety of systems, particularly the radiation polymerization of ethylene.

Since the inception of the Polymer. Concrete Program in 1965, Lawrence has been greatly involved in its development. He is currently head of the Process Materials Group in the Process Sciences Division of the Department of Applied Science. Lawrence won the American Concrete Institute's Wasson medal award in 1971 for noteworthy research in the field of polymer concrete.

On many fall weekends, Lawrence referees college football games in the Northeast. He lives in Port Jefferson with his wife Betsy and his three daughters. 